\title{
A transcript-wide association study in physical activity intervention implicates molecular pathways in chronic disease
}

\section{Kajal Claypool ${ }^{1}$ and Chirag J Patel ${ }^{1,+}$}

${ }^{1}$ Department of Biomedical Informatics, Harvard Medical School, 10 Shattuck St., Boston, MA. 02115

+Corresponding author: chirag_patel@hms.harvard.edu

\begin{abstract}
Background

Physical activity is associated with decreased risk for several chronic and acute conditions including obesity, diabetes, cardiovascular disease, mental health and aging. However, the biological mechanisms associated with this decreased risk are elusive. One way to ascertain biological changes influenced by physical activity is by monitoring changes in how genes are expressed. In this investigation, we conducted a transcriptome-wide association study of physical activity, meta-analyzing 20 independent studies to increase power for discovery of genes expressed before and after physical activity. Further, we hypothesize that genes identified in physical activity are expressed in obesity, inflammation, major depressive disorder and healthy aging.

Results

Our analysis identified thirty (30) transcripts induced by physical activity (PA signature), at an FDR $<0.05$. Twenty (20) of these transcripts, including COL4A3, CAMKD1, SLC4A5, EPS15L1, RBM33, and CACNG1, are up-regulated and ten (10) transcripts including CRY1, ZNF346, SDF4, ANXA1 and YWHAZ are down-regulated. We find that several of these physical activity transcripts are associated and biologically concordant in direction with body mass index, white blood cell count, and healthy aging.

Conclusions powerful approach, we found thirty genes that were putatively influenced by physical activity, eight of which are inversely associated with body mass index, thirteen inversely associated with white blood cell count, and three associated and concordant with healthy aging. One gene was significant and concordant with major depressive disorder. These results highlight the potential molecular basis for the protective benefit of physical activity for a broad set of chronic conditions.
\end{abstract}




\section{Background}

Physical activity is associated with decreased risk for obesity ${ }^{1,2}$, aging ${ }^{3-6}$, all-cause mortality ${ }^{7}$, cardiovascular disease $^{8-10}$, hypertension ${ }^{11-13}$, age-related diseases ${ }^{14-19}$, type 2 diabetes mellitus ${ }^{20-23}$, esophageal cancer ${ }^{24}$, colon cancer $^{25,26}$, breast cancer ${ }^{27}$, and anxiety and depression ${ }^{28}$. However, while there is strong evidence of the effectiveness of regular physical activity in the prevention of these chronic and acute conditions and premature death ${ }^{12}$, the molecular mechanisms that underlie this protective effect of physical activity are not fully understood. As chronic conditions such as diabetes and obesity reach epidemic status ${ }^{29-31}$, there is a pressing need to gain better understanding of the molecular mechanisms that govern physical activity. Such an understanding can lead to more effective treatment plans, reducing patient risk for multiple chronic conditions.

In the past decade, researchers have used gene expression microarrays to identify functional changes associated with disease and behavior. In fact, several ${ }^{32-39}$ have used microarrays to measure the differential change in gene expression before and after exercise. However, while these investigations have identified putative gene signatures of physical activity, the results are not consistent across the different studies, potentially attributed to small sample sizes, diversity of tissues, exercise intervention protocol, and variations in demographics of the participants. To address these challenges, we conducted a meta-analysis of existing interventional investigations that assay gene expression before and after physical activity. Our large-scale meta-analysis attempts to identify cross-tissue, cross-exercise-type gene expression changes induced by physical activity. We claim that both anaerobic and aerobic activity interventions induce a common set of gene expression changes across tissues, such as peripheral blood mononuclear cells (PBMCs) and muscle. Second, we claim that the molecular changes induced by physical activity are associated with chronic disease. In total, we meta-analyzed 20 independent studies $(n=820)$. We then queried the role of these genes and their association with obesity, inflammation, major depressive disorder and aging to enhance explanation of the observed therapeutic effects of physical activity.

We identified thirty $(30)$ genes to be significantly differentiated (false discovery rate $($ FDR $)<0.05$ ) after physical activity intervention, with twenty (20) genes up-regulated and ten (10) genes down-regulated. A subset of these genes were significantly associated and biologically relevant for body mass index, white blood cell count and healthy aging. We found one gene associated and concordant with major depressive disorder.

Our work represents, to the best of our knowledge, the largest meta-analysis identifying changes in gene expression associated with physical activity. This physical activity gene expression signature may offer insights into the pathophysiological mechanisms that underlie the potential therapeutic benefits of physical activity observed for a broad swath of chronic conditions.

\section{Methods}

Our overall method is described in Figure 1 (a). We first identified the transcripts differentially expressed after a physical activity intervention. For this, we conducted a large scale meta-analysis ${ }^{40-43}$ over 820 samples drawn from twenty distinct studies. We next attempted to identify the biological significance of genes associated with physical activity in traits such as body mass index (a risk factor for chronic disease), white blood cell count (a marker for inflammation and risk or result of chronic disease), major depressive disorder, and biological aging.

\section{Data Collection}

We cataloged and downloaded gene expression and sample data from twenty (20) publicly available microarray studies that assayed gene expression before and after physical activity in healthy participants. We selected these studies from Gene Expression Omnibus $(\mathrm{GEO})^{44}$ and ArrayExpress ${ }^{45}$ using the query terms exercise [ALL], physical activity [ALL], VO2 [ALL] and Homo sapiens [ORGN] (to select human gene expression data) and Expression profiling by array[Filter] (to select microarray studies). Our search query identified 177 studies in GEO and 23 studies in ArrayExpress. Twenty-one (21) of the ArrayExpress studies overlapped with the GEO studies resulting in a combined set of 179 studies with 5647 samples (Step (A) in Figure 1 (b)). See Supplementary File B for the full list of the 179 studies. We used the rentrez R package ${ }^{46}$ to execute the query on GEO and the ArrayExpress R package ${ }^{47}$ to execute the query on ArrayExpress. 


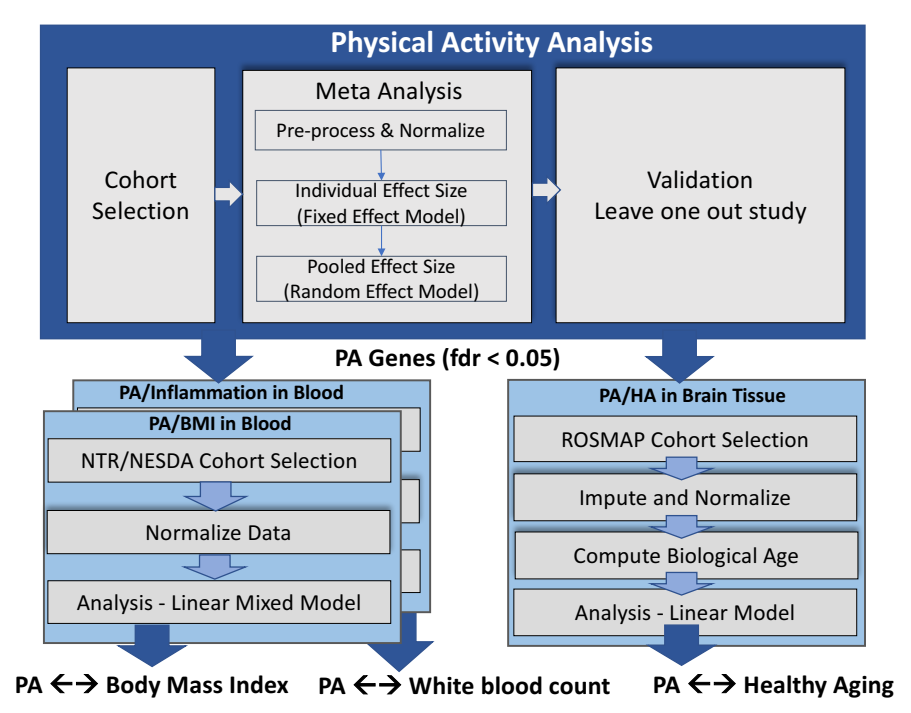

(a) Methodology

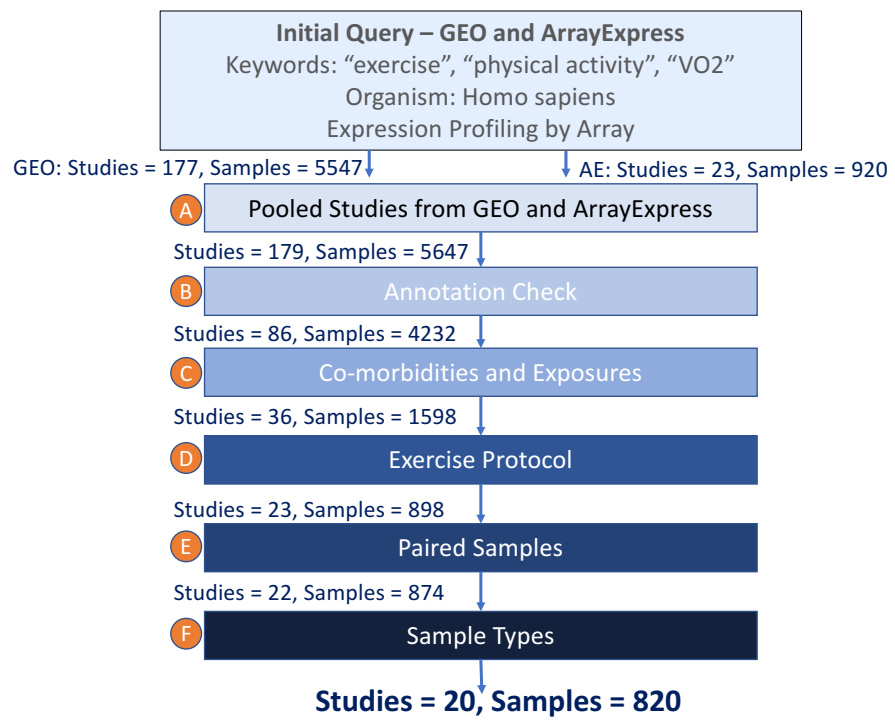

(b) PA Study Selection

Figure 1. (a) Overall Methodology for the Study. (b) Physical Activity Study Selection - Microarray studies from Gene Expression Omnibus (GEO) and ArrayExpress.

We curated these 179 studies using the selection criteria highlighted in Figure 1 (b). First, to ensure uniform transcript-level analysis, we verified that there were known probe to transcript annotations based on GPL annotation and the information available in GEOmetaDB ${ }^{48}$. This resulted in a total of 86 studies with 4292 samples (Step (B) in Figure 1 (b)). Next, we eliminated studies that included co-morbidities and/or exposures prior to exercise to minimize confounding. Fifty studies with a total 2694 samples were filtered out in this step (Step (C)). In Step (D), we verified that the investigation either intervened with aerobic (AR) exercise intervention, defined as participants achieving $70 \%$ to $90 \%$ of their peak heart rate and exercised for at least 30 minutes $^{49,50}$; or anaerobic (AN), where participants trained 2 to 3 times per week ${ }^{51}$. We filtered out studies that did not conform to these criteria, leaving 23 studies with a total of 898 samples. Next, to eliminate time-invariant confounding, we selected studies with paired data, that is gene expression before and after physical activity. This resulted in 22 studies and 874 samples (Step (E)). Finally, we selected studies where the sample types corresponded to tissues in GTex ${ }^{52}$. Two studies conducted on natural killer (NK) cells were removed at this last step (Step (F)). Overall, we identified twenty (20) microarray datasets that conformed to our selection criteria with a total of 820 samples (410 paired samples). Table 1 provides overall statistics for the selected studies while Table 2 details the selected studies.

\begin{tabular}{|c|c|c|c|c|}
\hline & Number of Studies & Number of Samples & Sex Distribution & GPL \\
\hline All & 20 & 820 & $\sigma^{x}: 471, q: 176, ?: 173$ & $96,570,571,6244,10558,11532$ \\
\hline Aerobic & 16 & 613 & $\mathrm{o}^{x}: 369$, , ᄋ:160, ?:84 & $96,570,571,6244,10558$ \\
\hline Anaerobic & 4 & 209 & $\sigma^{7}: 102$, o:16, ?:89 & $570,6244,11532$ \\
\hline
\end{tabular}

Table 1. Meta Analysis study statistics at a glance.

We harmonized the gene expression data from each study to include expression data for transcripts that were common to all datasets. All data was normalized and $\log 2$ transformed using Robust Multichip Averaging (RMA) ${ }^{53}$ implemented in the Affy package and batch corrected using ComBat ${ }^{54}$. 


\begin{tabular}{|c|c|c|c|c|c|c|}
\hline & GSE & GPL & Study Title & $\begin{array}{l}\text { Num } \\
\text { Samples }\end{array}$ & Sample Type & Study Type \\
\hline 1 & GSE1786 & 96 & $\begin{array}{l}\text { Vastus lateralis biopsies from healthy trained } \\
\text { and sedentary males }\end{array}$ & 24 & Vastus lateralis & $\begin{array}{l}\text { Aerobic } \\
\text { (AR) }\end{array}$ \\
\hline 2 & GSE1140 & 96 & PMBCs and the effect of exercise & 15 & PBMC & $\begin{array}{l}\text { Aerobic } \\
(\mathrm{AR})\end{array}$ \\
\hline 4 & GSE8668 & 570 & Neutrophil response to aerobic exercise & 24 & Neutrophils & $\begin{array}{l}\text { Aerobic } \\
\text { (AR) }\end{array}$ \\
\hline 5 & GSE51835 & 570 & $\begin{array}{l}\text { Effects of exercise on gene expression level } \\
\text { in human monocytes }\end{array}$ & 24 & PBMC & $\begin{array}{l}\text { Aerobic } \\
(\mathrm{AR})\end{array}$ \\
\hline 6 & GSE27536 & 570 & $\begin{array}{l}\text { Vastus lateralis biopsies from healthy and } \\
\text { COPD patients before and after } 8 \text { weeks of } \\
\text { exercise training }\end{array}$ & 54 & Vastus lateralis & $\begin{array}{l}\text { Aerobic } \\
(\mathrm{AR})\end{array}$ \\
\hline 7 & GSE47881 & 570 & $\begin{array}{l}\text { Impact of resistance exercise on human } \\
\text { skeletal muscle gene expression - aging }\end{array}$ & 89 & Skeletal Muscle & $\begin{array}{l}\text { Anaerobic } \\
\text { (AN) }\end{array}$ \\
\hline 8 & GSE24235 & 570 & $\begin{array}{l}\text { Skeletal muscle gene expression in response } \\
\text { to resistance exercise: sex specific regulation }\end{array}$ & 28 & Vastus lateralis & $\begin{array}{l}\text { Anaerobic } \\
\text { (AN) }\end{array}$ \\
\hline 9 & GSE14642 & 570 & $\begin{array}{l}\text { A Brief Bout of Exercise Alters Gene Expres- } \\
\text { sion and Distinct Gene Pathways in PBMC } \\
\text { of Early- and Late-Pubertal Females }\end{array}$ & 40 & PBMC & $\begin{array}{l}\text { Aerobic } \\
(\mathrm{AR})\end{array}$ \\
\hline 10 & GSE11761 & 570 & $\begin{array}{l}\text { Brief bout of exercise alters gene expres- } \\
\text { sion in peripheral blood mononuclear cells } \\
\text { of early- and late-pubertal males }\end{array}$ & 40 & PBMC & $\begin{array}{l}\text { Aerobic } \\
(\mathrm{AR})\end{array}$ \\
\hline 11 & GSE6053 & 571 & $\begin{array}{l}\text { Exhaustive exercise effect on peripheral } \\
\text { blood mononuclear cells and T lymphocytes }\end{array}$ & 12 & PBMC & $\begin{array}{l}\text { Aerobic } \\
\text { (AN) }\end{array}$ \\
\hline 12 & GSE4251 & 571 & $\begin{array}{l}\text { Gene expression profiles in white blood cell } \\
\text { subgroups }\end{array}$ & 18 & PBMC & $\begin{array}{l}\text { Aerobic } \\
\text { (AR) }\end{array}$ \\
\hline 13 & GSE3606 & 571 & $\begin{array}{l}\text { Exercise affects the gene expression profiles } \\
\text { of human white blood cells }\end{array}$ & 20 & PBMC & $\begin{array}{l}\text { Aerobic } \\
\text { (AR) }\end{array}$ \\
\hline 14 & GSE59088 & 6244 & $\begin{array}{l}\text { Human skeletal muscle transcriptome re- } \\
\text { sponses to differentiated exercise }\end{array}$ & 54 & Vastus lateralis & $\begin{array}{l}\text { Anaerobic } \\
\text { (AN) }\end{array}$ \\
\hline 15 & GSE57999 & 6244 & $\begin{array}{l}\text { Expression data from baseline and post- } \\
\text { endurance training in human PBMCs }\end{array}$ & 26 & PBMC & $\begin{array}{l}\text { Aerobic } \\
(\mathrm{AR})\end{array}$ \\
\hline 16 & GSE46075 & 6244 & $\begin{array}{l}\text { Dynamically regulated miRNA-mRNA net- } \\
\text { works revealed by exercise }\end{array}$ & 56 & PBMC & $\begin{array}{l}\text { Aerobic } \\
(\mathrm{AR})\end{array}$ \\
\hline 17 & GSE34788 & 6244 & $\begin{array}{l}\text { Genomic signatures of a global fitness index } \\
\text { in a multi-ethnic cohort of women }\end{array}$ & 120 & PBMC & $\begin{array}{l}\text { Aerobic } \\
(\mathrm{AR})\end{array}$ \\
\hline 18 & GSE28498 & 6244 & $\begin{array}{l}\text { Passing the anaerobic threshold is associated } \\
\text { with substantial changes in the gene expres- } \\
\text { sion profile in white blood cells }\end{array}$ & 52 & PBMC & $\begin{array}{l}\text { Aerobic } \\
(\mathrm{AR})\end{array}$ \\
\hline 19 & GSE43856 & 10558 & $\begin{array}{l}\text { Changes in the transcriptome of circulating } \\
\text { neutrophils and skeletal muscle in response } \\
\text { to endurance exercise }\end{array}$ & 64 & $\begin{array}{l}\text { Vastus lateralis } \\
\& \text { neutrophils }\end{array}$ & $\begin{array}{l}\text { Aerobic } \\
\text { (AR) }\end{array}$ \\
\hline 20 & GSE41769 & 11532 & $\begin{array}{l}\text { Effects of acute exercise on gene expres- } \\
\text { sion in exercising and non-exercising human } \\
\text { skeletal muscle }\end{array}$ & 36 & Vastus lateralis & $\begin{array}{l}\text { Anaerobic } \\
\text { (AN) }\end{array}$ \\
\hline
\end{tabular}

Table 2. Selected studies from Gene Expression Omnibus. Each study provided paired gene expressions corresponding to before and after physical activity.

\section{Meta-Analysis - Physical Activity Effect Size Computation}

Our goal was to compute the pooled/combined effect size for each transcript across the selected twenty studies. For this, we first computed the individual study effect size (corrected Hedges' $g$ ) for each transcript using the paired samples. We used a fixed-effects model to combine gene expression values where multiple probes mapped to the 
same transcript. We next used a random-effects model to combine effect sizes across the studies. Specifically, we used the DerSimonian-Laird random effects model ${ }^{55}$ wherein the pooled effect size, $\hat{\theta}_{F}$, is given as the weighted average of the individual effect effect sizes from each study. That is,

$$
\hat{\theta}_{F}=\frac{\sum_{i=1}^{K} w_{i} \hat{\theta}_{i}}{\sum_{i=1}^{K} w_{i}}
$$

And the weights are given as:

$$
w_{i}^{*}=1 /\left(\hat{\tau}^{2}+\hat{\sigma}^{2}\right)
$$

where $\hat{\tau}^{2}$ is the measure of the inter-study heterogeneity and $\hat{\sigma}^{2}$ are the variances of each study's effect size estimate $\hat{\theta}_{i}$. For each pooled effect size, we tested for the null hypothesis of no effect $\left(\hat{\theta}_{i}=0\right)$, and the null hypothesis of no heterogeneity $\left(\hat{\tau}^{2}=0\right)$. To control for multiple hypothesis testing we computed the Benjamini-Hochberg $(\mathrm{BH})$ false discovery rate (FDR), the estimated proportion of the discoveries made that were false. We used the R package metafor ${ }^{56}$ to estimate the pooled effect size, the significance and the inter-study heterogeneity. We tested the inter-study heterogeneity using a Chi-square distribution with $\mathrm{k}-1$ degrees of freedom.

We next used a two-step method to identify the significant transcripts from the meta-analysis. First, we identified differentially expressed transcripts, $\mathscr{T}$. We considered the transcript $t \in \mathscr{T}$ significant if the absolute value of the pooled effect size of the transcript $t$ was greater than $0\left(\hat{\theta}_{t}>0\right)$, the false discovery rate (FDR) less than $0.05\left(\right.$ FDR $_{t}$ $<0.05)$ and the inter-study heterogeneity $\left(\hat{\tau}^{2}=0\right)$ accounted for less than $50 \%$ of the variability in point estimates or was not highly significant $(\mathrm{p}<0.0001)^{57}$. To ensure that our findings were not driven by any single study, we next conducted a leave one out sensitivity analysis by iteratively removing one (1) study at a time ${ }^{42}$. Transcripts discovered in Step 1, T, were considered valid and robust, if they had a $\mathrm{p}<0.05$ across all leave-one-study out analyses. We report physical activity genes surviving the leave-one-out analysis as the PA signature.

\section{Physical Activity and Phenotype Association}

We correlated the PA signature genes with body mass index, white blood cell count and major depressive disorder in monozygotic and dizygotic twins. Finally, we interrogated the association between PA signature genes, measured by RNASeq, and brain tissue epigenetic age, measured by genome-wide methylation arrays. We defined age deceleration ("healthy aging") as the difference between chronological age and epigenetically predicted age ${ }^{58}$.

\section{Phenotype Cohorts}

We interrogated the Netherlands Twin Registry (NTR) and the Netherlands Study of Depression and Anxiety (NESDA) twin cohort to determine the association between PA signature genes and body mass index, white blood cell count and major depressive disorder. The NTR/NESDA twin cohort provides clinical and gene expression measurements on 2561 twin pairs. Clinical phenotypes available in the data set include demographic variables, age, sex, body mass index (BMI), clinical markers like white blood cell count (WBC) and neutrophil count, and clinical diagnosis of major depressive disorder (MDD), together with information on twin zygosity and family (see Table 3 for summary statistics). The dataset was downloaded from the dbGaP website, under pht002805.v1.p1(https://www.ncbi.nlm.nih.gov/gap/?term=pht002805.v1.p1) and normalized prior to analysis.

To determine the association between physical activity and brain aging, we used the longitudinal clinicalpathologic study of aging and Alzheimer's disease (AD) from Rush University (ROSMAP). The ROSMAP dataset is a collection of data from two separate studies conducted by the Rush University. ROS is a longitudinal clinicalpathologic cohort with individuals from 40 different religious orders across the United States. MAP is a longitudinal, epidemiologic clinical-pathologic cohort study of common chronic conditions of aging and Alzheimer's disease. We merged clinical, RNASeq and DNA Methylation data to analyze the association of PA signature genes with aging. ROSMAP clinical data includes clinical, pathology and demographic data including age at time of death, sex and years of education for 1102 individuals. RNA Seq data, generated from RNA extracted from the gray matter of the dorsolateral prefrontal cortex, contain fragments per kilobase of transcript per million mapped reads 


\begin{tabular}{rrr}
\hline Variable & NTR/NESDA & ROSMAP Cohort \\
\hline \# Samples & 2561 & 547 \\
Tissue & Blood & Brain \\
Age & $34.69 \pm 11.59$ & $86.75 \pm 5.10$ \\
Sex & $0^{7}: 881$, $: 1680$ & $0^{\top}: 199$ q:348 \\
BMI & $23.86 \pm 4.28$ & - \\
WBC & $6.46 \pm 2.06$ & - \\
MDD & No MDD:2504, MDD:57 & - \\
Zygosity & MZ:1344, DZ:1217 & Not Applicable \\
Education & - & $16.48 \pm 3.47$ \\
APOE Mutation & - & Yes:134, No: 413 \\
\hline
\end{tabular}

Table 3. Summary Statistics for the NTR/NESDA and ROSMAP Cohort

(FPKM) for 640 subjects from the ROS and MAP cohorts. RNA Sequencing was done using Illumina HiSeq, and data was normalized and batch-corrected. Lastly, we also made use of the DNA Methylation data from ROSMAP. DNA methylation was performed on prefrontal cortex samples collected from 740 individuals using the Illumina HumanMethylation450 BeadChip. Figure 2 outlines the merging steps we used to generate the cohort for age deceleration/ age deceleration analysis. (See Table 3 for summary statistics). ROSMAP study data were provided by the Rush Alzheimer's Disease Center, Rush University Medical Center, Chicago.

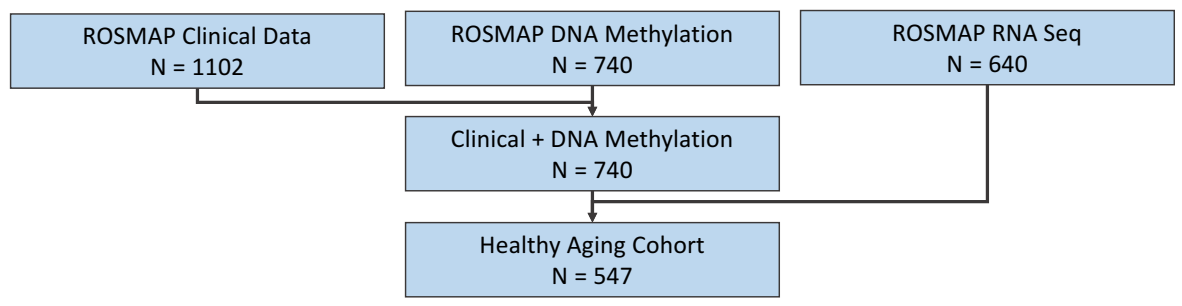

Figure 2. Selection of cohort from ROSMAP for Age Deceleration.

\section{Associating PA Signature Genes with Phenotypes}

Linear Mixed Models: Body mass index, White blood cell count and Major depressive disorder. We associated the physical activity transcripts (PA signature genes) in the twin cohort data (NTR/NESDA) with body mass index (BMI), white blood cell count (WBC) and major depressive disorder (MDD). Specifically, we regressed body mass index (BMI) on each of the physical activity genes identified by the leave-one-study out validation step (PA signature genes) ( $g \in P A$ Signature), adjusting for fixed effects of age and sex, and random effects of family and twin monozygosity. One random effect accounted for variation within families and another for monozygotic twins resulting in a linear mixed model ${ }^{59,60}$ of the form:

$$
B M I \sim g+\text { Age }+ \text { Sex }+(1 \mid \text { Family })+(1 \mid M Z)
$$

We interrogated the NTR/NESDA twins to identify associations between physical activity genes and white blood cell count, an indicator of inflammation. In addition to age and sex, we adjusted the models for BMI and smoking status to measure the association of physical activity with white blood cell count independent of BMI and smoking status $^{61-64}$. We also adjusted the model for the random effects for family and monozygosity resulting in:

$$
W b c \sim g+\text { Age }+ \text { Sex }+B M I+\text { SmokingStatus }+(1 \mid \text { Family })+(1 \mid M Z)
$$


Further, we tested the twin cohort for association between physical activity and major depressive disorder. We adjusted the MDD models for age, sex and alcohol consumption, a known depressant ${ }^{65}$ resulting in models of the form:

$$
M D D \sim g+\text { Age }+ \text { Sex }+ \text { Alcohol }+(1 \mid \text { Family })+(1 \mid M Z)
$$

We used the $\mathbf{R}$ package $l \mathrm{me} 4^{66}$ and $l$ merTest ${ }^{67}$ for our linear mixed model, and $\mathrm{r} 2 \mathrm{~g} l \mathrm{~mm}^{67}$ to compute the $\mathrm{R}^{2}$ using the Nakagawa and Schielzeth approach. We report the summary effect size of all PA genes that were found to be significant in our mixed model analysis at $\mathrm{p}<0.05$.

Linear Model: Epigenetic Aging. To perform the association analysis for biological aging, and in particular healthy aging (HA) of the brain, we first computed the epigenetic or biological age for all samples in our healthy aging cohort $(\mathrm{N}=547)$ with 353 epigenetic markers to compute the biological age ${ }^{58}$. Three out of the 353 epigenetic markers were missing $(<1 \%)$. We imputed these missing methylation data using knn-imputation ${ }^{68}$ and normalized the DNA methylation data using BMIQ normalization ${ }^{69}$. We verified the predicted epigenetic age with the DNA methylation age calculator at https: //labs.genetics.ucla.edu/horvath/dnamage/. We created a new variable, HA, as the difference between chronological age and the estimated epigenetic age. The chronological age for all participants above 90 was hidden in the dataset (set to $90+$ ). We therefore set the age of all individuals above 90 to 91 . We then regressed HA on each of the PA signature genes using a linear model adjusted for sex and study (ROS or MAP study $)^{70}$ using a linear model of the form:

$$
H A \sim g+\text { Age }+ \text { StudyType }
$$

We report the summary effect size of all PA genes that were found to be significant in our analysis at $\mathrm{p}<0.05$.

For all three phenotypes, we also tested for enrichment of the PA signature genes in the genes associated with the phenotype using a hypergeometric distribution.

For reproducibility, the analysis scripts (code) used for this effort are available in a Git repository (https://kajalc@bitbucket.org/kajalc/physical-activity-analysis.git). Additionally, we have a R Shiny application available to facilitate further exploration of the results at http://apps.chiragjpgroup.org/pagex/.

\section{Results}

\section{Identifying genes differentially expressed with physical activity}

In our transcript-wide analysis of paired gene expression measurements, we found thirty (30) transcripts expressed (FDR $<0.05)$. Of the 30, twenty (20) were up-regulated and ten (10) transcripts were down-regulated (see Figure 3 and Table 4) after physical activity. Two (2) transcripts, COL4A3 (up-regulated) and SLC25A15 (down-regulated) were found to be significant at FDR $<0.01$. All thirty (30) transcripts were found to be consistently associated with physical activity in the leave one study out analysis. Figure 4 shows the individual study and pooled effect sizes of the top four (4) transcripts (by largest absolute effect size). For a comparison of effect sizes of all genes see Supplementary File A.

\section{Association with Body Mass Index}

Of the thirty (30) identified physical activity genes, seven (7) genes, C9orf131, CACNG1, EPS15L1, ANXA1, SSX2IP, PNP and YWHAZ, were significantly associated with body mass index $(\mathrm{p}<0.05)$, when adjusted for fixed effects of age and sex, and random effects due to family and monozygosity. We found one additional gene, SSPN, to be marginally significant $(\mathrm{p}=0.06)$. Furthermore, all genes were in biologically concordant directions (i.e., down-regulated in PA and up-regulated in BMI and vice versa). Specifically, increased expression of up-regulated PA signature genes, C9orf131, CACNG1 and EPS15L1 were all associated with lower BMI. A one unit increase in the expression of EPS15L1, for instance, was associated with a -0.35 unit decrease in BMI (95\% CI: -0.586 , -0.114). Increased expression of down-regulated PA signature genes ANXA1, PNP, SSX2IP and $Y W H A Z$, on the other hand, were associated with increased BMI. We found that SSX2IP is associated with the largest increase in BMI, with a one unit increase in the expression of SSX2IP associated with a 0.41-unit increase in BMI (95\% CI: 


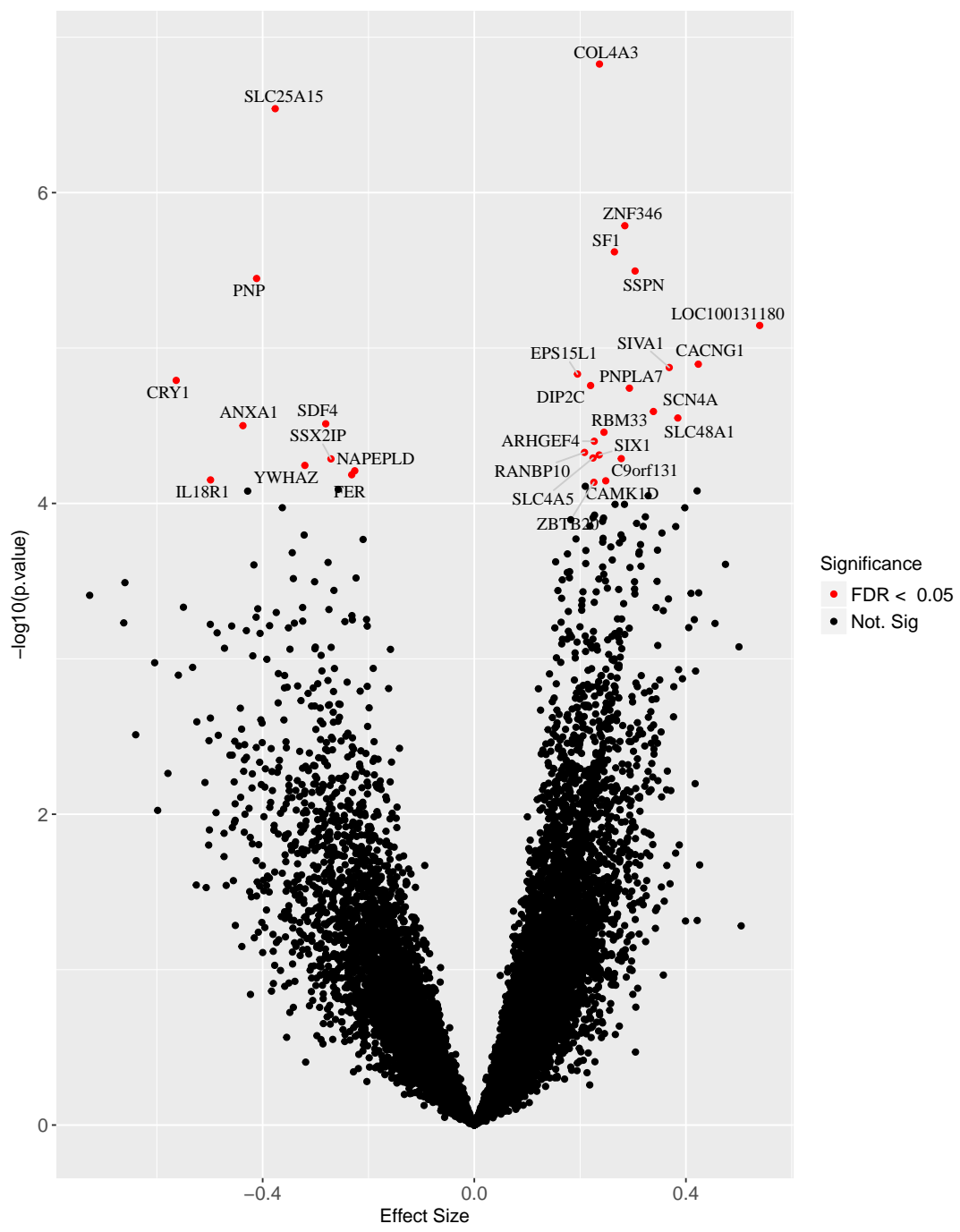

Figure 3. Up- and Down- regulated genes identified by paired meta-analysis of gene expressions taken from blood and muscle tissue $(\mathrm{N}=820)$. Genes significant at false discovery rate $<0.05$ are shown in red.

0.077, 0.743). Figure 5 (a) summarizes the effect sizes of the PA signature genes significantly associated with BMI. All eight PA signature genes were inversely associated with body mass index. The variance explained in body mass index by physical activity genes was $8 \%$ (95\% CI: 0.066, 0.106). Removing physical activity genes from the model significantly reduced the goodness of fit, as indicated by likelihood ratio test - effect of PA genes: $\chi^{2}(30)=67.41$, $\mathrm{p}<6.78 e^{-05}$. A hypergeometric test to evaluate the enrichment of PA signature in BMI was nominally significant $(\mathrm{P}(\mathrm{x} \geq 8)=0.04)$.

\section{Association with White Blood Cell Count}

We found thirteen (13) PA signature genes to be significantly associated with white blood cell count $(\mathrm{p}<0.05)$, when adjusted for fixed effects of age, sex, BMI, smoking status, and random effects of family and monozygosity. Twelve of these significantly associated transcripts were in biologically concordant directions with physical activity. Specifically, we found increased expressions of up-regulated physical activity genes, CACNG1, DIP2C, RANBP10, SCN4A, SF1, SLC48A1, SLC4A5, ZBTB20 and ZNF346, were associated with a decrease in white blood cell count. A one unit increase in the expression of ZNF346, for example, was associated with a 0.54 decrease in white blood cell count. Increased expressions of down-regulated PA signature genes, however, were associated with increased 


\begin{tabular}{|c|c|c|c|c|}
\hline Gene & Description & Effect Size & FDR & Direction \\
\hline ARHGEF4 & Rho Guanine Nucleotide Exchange Factor 4 & 0.23 & 0.04 & 介 \\
\hline C9orf131 & Chromosome 9 Open Reading Frame 131 & 0.28 & 0.04 & 介 \\
\hline CACNG1 & $\begin{array}{l}\text { Calcium Voltage-Gated Channel Auxiliary } \\
\text { Subunit Gamma } 1\end{array}$ & 0.42 & 0.029 & $\Uparrow$ \\
\hline CAMK1D & $\begin{array}{l}\text { Calcium/Calmodulin Dependent Protein Ki- } \\
\text { nase ID }\end{array}$ & 0.25 & 0.05 & 介 \\
\hline COL4A3 & Collagen Type IV Alpha 3 Chain & 0.24 & 0.003 & 介 \\
\hline DIP2C & Disco Interacting Protein 2 Homolog C & 0.22 & 0.03 & 介 \\
\hline EPS15L1 & $\begin{array}{l}\text { Epidermal Growth Factor Receptor Pathway } \\
\text { Substrate } 15 \text { Like } 1\end{array}$ & 0.19 & 0.03 & $\Uparrow$ \\
\hline LOC100131180 & & 0.54 & 0.02 & 介 \\
\hline PNPLA7 & $\begin{array}{l}\text { Patatin Like Phospholipase Domain Contain- } \\
\text { ing } 7\end{array}$ & 0.29 & 0.03 & $\Uparrow$ \\
\hline RANBP10 & RAN Binding Protein 10 & 0.21 & 0.04 & 介 \\
\hline RBM33 & RNA Binding Motif Protein 33 & 0.25 & 0.04 & 介 \\
\hline SCN4A & $\begin{array}{l}\text { Sodium Voltage-Gated Channel Alpha Subunit } \\
4\end{array}$ & 0.34 & 0.04 & $\Uparrow$ \\
\hline SF1 & Splicing Factor 1 & 0.26 & 0.01 & 介 \\
\hline SIVA1 & SIVA1 Apoptosis Inducing Factor & 0.37 & 0.03 & $\Uparrow$ \\
\hline SIX1 & SIX Homeobox 1 & 0.24 & 0.04 & $\Uparrow$ \\
\hline SLC48A1 & Solute Carrier Family 48 Member 1 & 0.38 & 0.04 & 介 \\
\hline SLC4A5 & Solute Carrier Family 4 Member 5 & 0.22 & 0.04 & $\Uparrow$ \\
\hline SSPN & Sarcospan & 0.30 & 0.01 & 介 \\
\hline ZBTB20 & Zinc Finger And BTB Domain Containing 20 & 0.23 & 0.05 & $\Uparrow$ \\
\hline ZNF346 & Zinc Finger Protein 346 & 0.28 & 0.01 & $\Uparrow$ \\
\hline ANXA1 & "Annexin A1 & 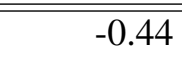 & 0.04 & 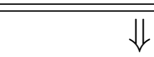 \\
\hline CRY1 & Cryptochrome Circadian Clock 1 & -0.56 & 0.03 & $\Downarrow$ \\
\hline FER & FER Tyrosine Kinase & -0.23 & 0.05 & $\Downarrow$ \\
\hline IL18R1 & Interleukin 18 Receptor 1 & -0.49 & 0.05 & $\Downarrow$ \\
\hline NAPEPLD & $\begin{array}{l}\text { N-Acyl Phosphatidylethanolamine Phospholi- } \\
\text { pase D }\end{array}$ & -0.23 & 0.05 & $\Downarrow$ \\
\hline PNP & Purine Nucleoside Phosphorylase & -0.41 & 0.01 & $\Downarrow$ \\
\hline SDF4 & Stromal Cell Derived Factor 4 & -0.28 & 0.04 & $\Downarrow$ \\
\hline SLC25A15 & Solute Carrier Family 25 Member 15 & -0.38 & 0.003 & $\Downarrow$ \\
\hline SSX2IP & SSX Family Member 2 Interacting Protein & -0.27 & 0.04 & $\Downarrow$ \\
\hline YWHAZ & $\begin{array}{l}\text { Tyrosine 3-Monooxygenase/Tryptophan 5- } \\
\text { Monooxygenase Activation Protein Zeta }\end{array}$ & -0.32 & 0.04 & $\Downarrow$ \\
\hline
\end{tabular}

Table 4. Significant PA transcripts. Transcripts differentially expressed as a result of any type of physical activity with FDR $<0.05$ and surviving leave-one-out study analysis at $\mathrm{p}<0.05$.

counts of white blood cells, with for example, a one unit increase in $Y W H A Z$ expression associated with a 0.13 increase in white blood cell count. Figure 5 (b) summarizes the effect sizes of PA signature genes significantly associated with white blood cell counts compared with PA signature gene effect sizes. Overall, the physical activity genes explained $16 \%$ (95\% CI: 14.8, 19.8) of the variance in white blood cell count using a full model adjusted for fixed effects of age, sex, BMI, and smoking status and random effects of family and monozygosity. Physical activity genes significantly improved the goodness of fit, measured using a likelihood ratio test: $\chi^{2}(30)=192.84, p<2.2$ 


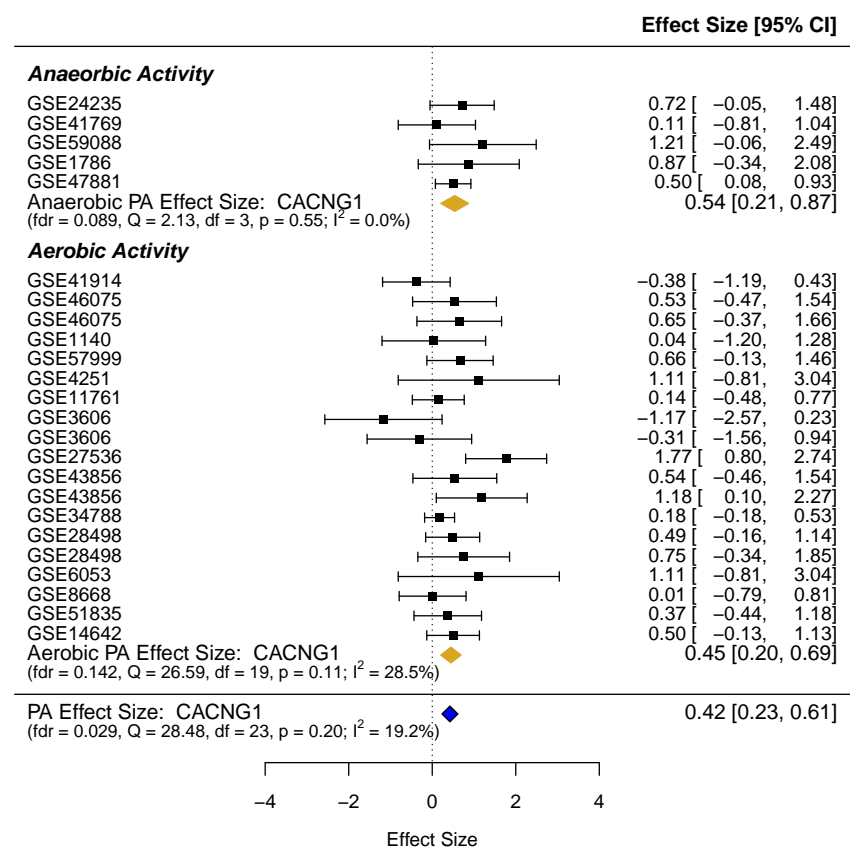

(a) CACNG1

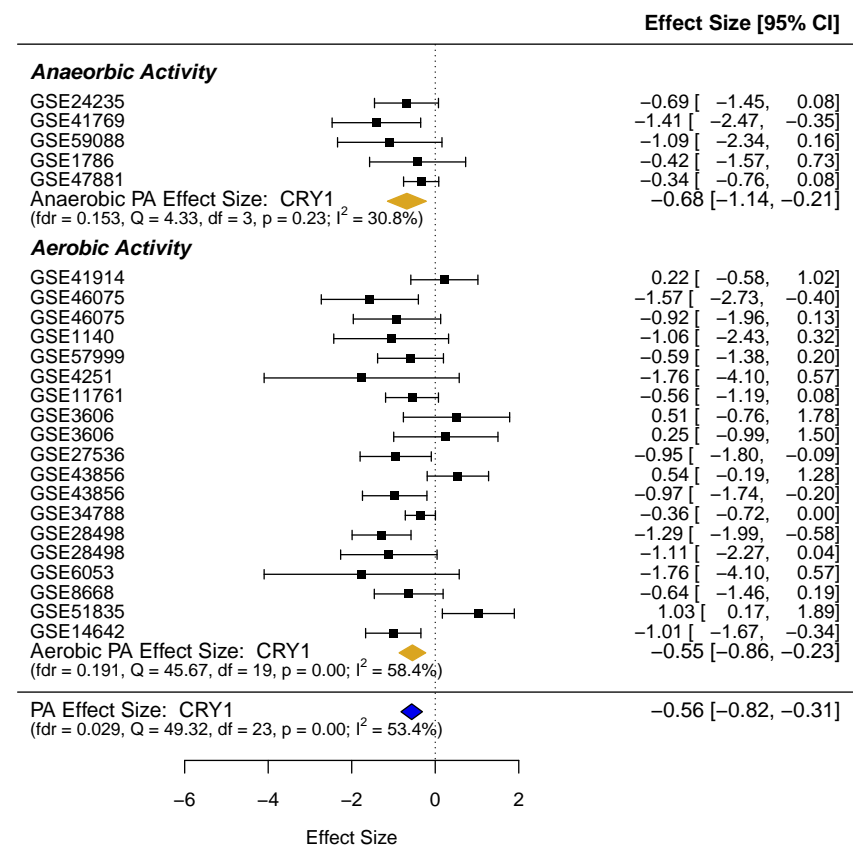

(c) CRY1

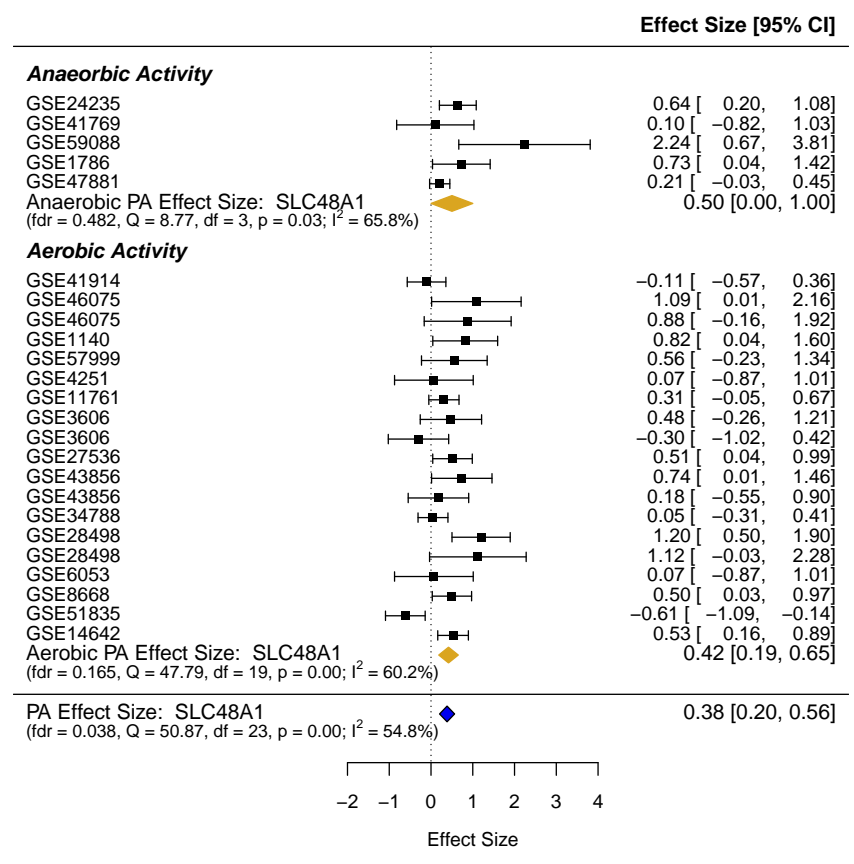

(b) SLC48A1

Effect Size $[95 \% \mathrm{Cl}]$

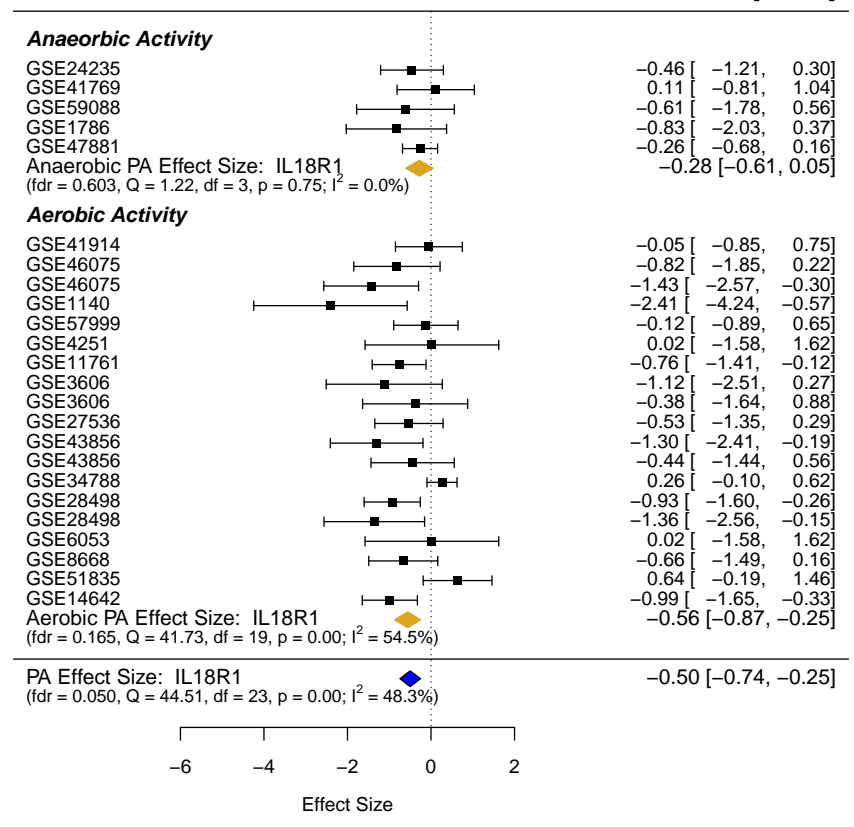

(d) IL18R1

Figure 4. Four differentially expressed genes with biggest effect sizes. For many of the studies, these genes were not significant within the individual studies but were shown to be significant in our meta-analysis.

$e^{-16}$. Further, we rejected our null hypothesis of no enrichment of PA genes associated with WBC (hypergeometric $\mathrm{P}(\mathrm{x} \geq 13)=0.000012)$.

We found one (1) PA gene, $S C N 4 A$, to be significantly associated $(\mathrm{p}<0.05)$ with major depressive disorder, 


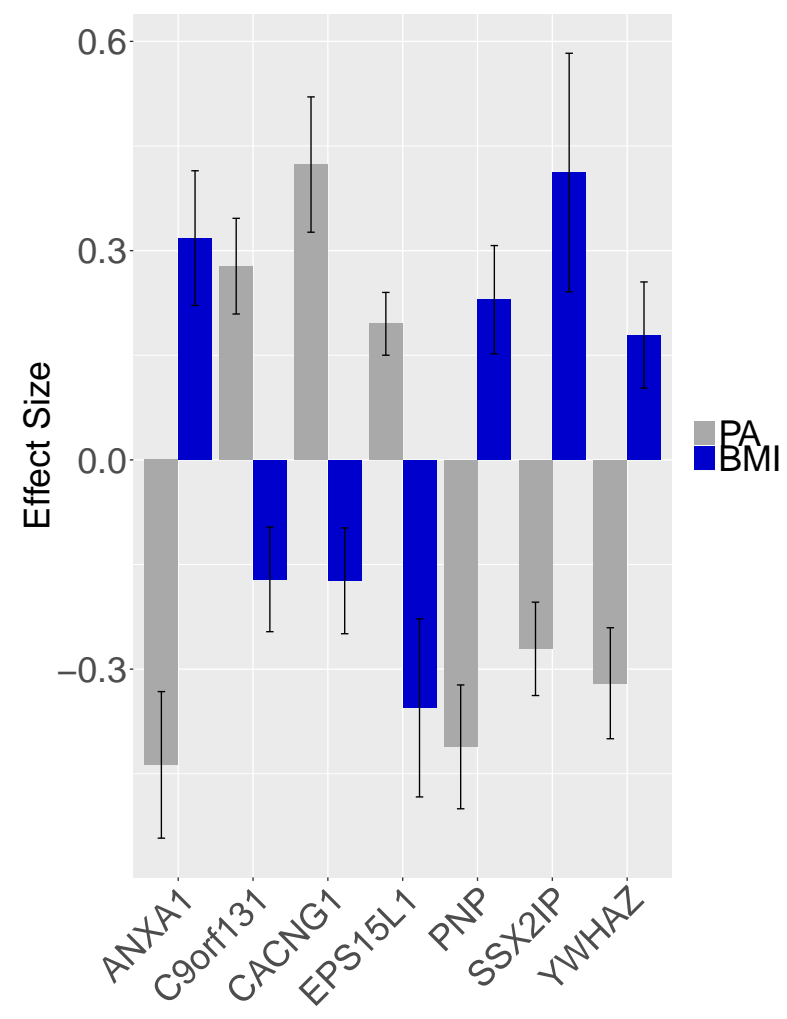

(a) PA and BMI

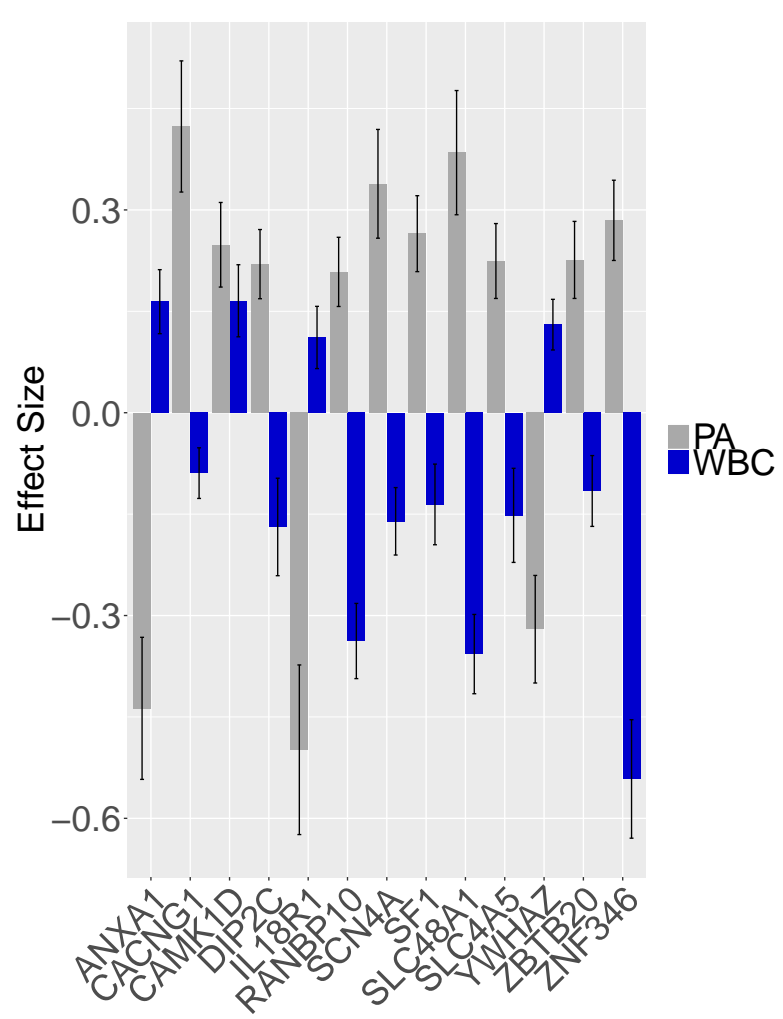

(b) PA and WBC

Figure 5. (a) Association of PA signature genes with body mass index. (b) Association of PA signature genes with white blood cell count.

when the models were adjusted for age, sex, alcohol and the random effects of family and monozygosity. See Supplementary File A for detailed results.

\section{Association with Age Deceleration}

We hypothesized that genes associated with physical activity are also associated with "healthy aging", or, age deceleration (the deviation of chronological age from epigenetic or biological age) in diverse tissues, such as brain. We used 353 epigenetic markers ${ }^{58}$ to determine the epigenetic age of the individuals in the ROSMAP cohort in brain tissue, and verified the epigenetic age predictor was predictive of chronological age. The correlation between the estimated epigenetic age and chronological age was 0.69 with an absolute median deviance of 20 (See Supplementary File A). We took the difference between the epigenetic and chronological age to indicate age acceleration ("unhealthy aging") or deceleration ("healthy aging"). We associated the difference between epigenetically predicted and chronological age with PA signature genes adjusting for sex and study (ROS vs MAP). Three PA signature genes, PNPLA7, SSPN and NAPEPLD were significantly associated $(\mathrm{p}<0.05)$ and directionally concordant with age deceleration (see Figure 6 (a). Specifically, expression of PNPLA7 and SSPN, up-regulated by physical activity, were associated with age deceleration, or equivalently, increased difference in chronological and biological age. A one SD unit increase in SSPN, Sarcospan, was associated with a 0.41-year (95\% CI: 0.12, 0.71) deceleration in aging. On the other hand, increased expression NAPEPLD, down regulated by physical activity, was associated with a decrease in healthy aging - a one SD unit increase in NAPEPLD was associated with a 0.26 year decrease in healthy aging (95\% CI: -0.45, -0.07). Overall, we found that the PA signature genes when adjusted for age and study explain $9 \%$ of the variance in age deceleration in the ROSMAP data with $\chi^{2}(30)=671.3, p<0.042$. The hypergeometric test was not significant $(\mathrm{p}=.12)$. 


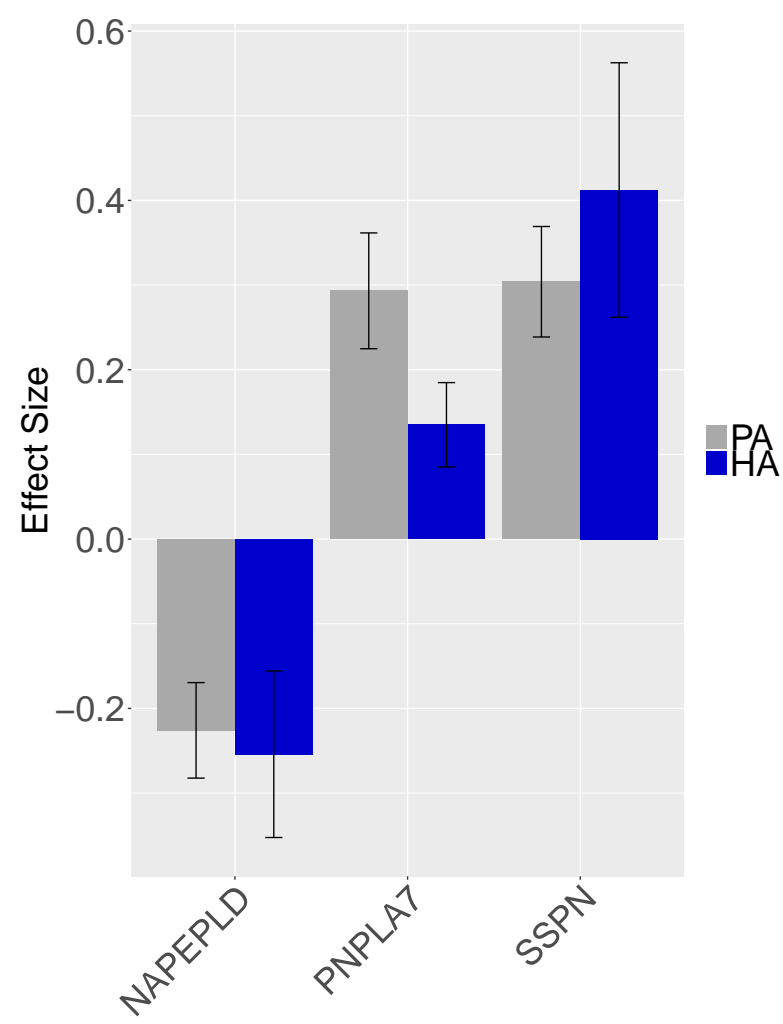

(a) PA and Age Deceleration

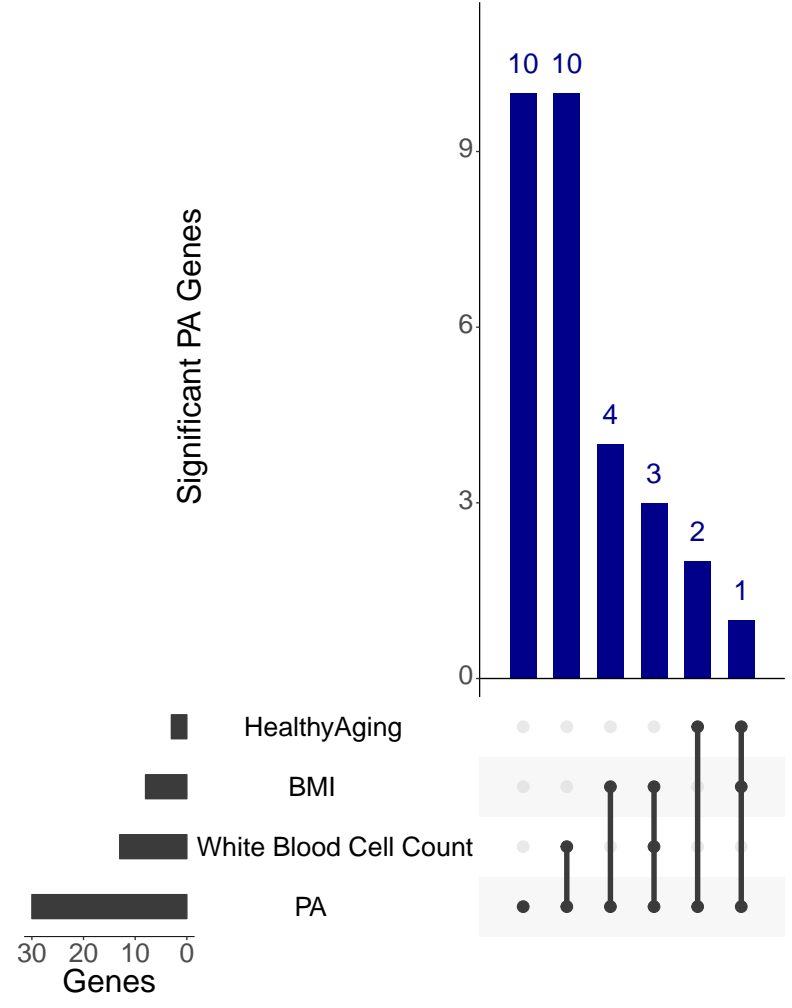

(b) Overlap: PA, BMI, WBC, HA

Figure 6. (a) Association of PA signature genes with age deceleration (healthy aging). (b) Overlap of PA signature genes across the three tested phenotypes, body mass index, white blood cell count and age deceleration.

Figure 6 (b) provides a summary of our key findings in terms of associations with the studied phenotypes: body mass index, white blood cell count and aging. We identified eight PA signature genes to be associated with BMI, thirteen associated with white blood cell count and three associated with aging. Of these YWHAZ( $\downarrow), \operatorname{ANXA1}(\downarrow)$ and CACGN1( $\uparrow)$ were associated with BMI and white blood cell count, while SSPN $(\uparrow)$ was associated with BMI in blood and aging in brain tissue.

\section{Discussion}

Our work sought to identify changes in gene expression due to aerobic and anaerobic physical activity intervention by meta-analyzing 20 independent interventional gene expression studies. Second, we examined the biological relevance of the physical activity genes associated with differences in BMI, WBC, and MDD in monozygotic and dizygotic twins. Third, we examined the association between the PA signature and epigenetic aging of the brain. These 30 PA-associated genes have been implicated in different phenotypes in multiple GWASs and mouse model knockout systems. For example, $C O L 4 A 3$, part of the collagen trimerization and phospholipase-C pathways, has been linked to kidney diseases and cancers ${ }^{71,72}$, while $S L C 4 A 5$, a sodium bicarbonate transporter has been associated with hypertension ${ }^{73-75}$. Overall, the PA genes have been associated with cardiovascular disease, adiposity, neurological, behavioral, and mortality and aging (See Supplementary File B for DisGeNET ${ }^{76}$ results). We describe specific associations in the following.

\section{Physical Activity associated gene expression and their correlation with BMI}

We identified eight (8) PA signature genes, C9orf131, CACNG1, EPS15L1, SSPN, ANXA1, SSX2IP, PNP and $Y W H A Z$, to be associated with body mass index in twins. All eight of these transcripts were directionally discordant 
with physical activity, that is transcripts up-regulated in physical activity were down-regulated in body mass index and vice versa. Transcripts $A N X A 1, P N P, S S P N$ and $Y W H A Z$ have all been previously associated with disorders of metabolism. ANXA1, Annexin A1, is a calcium and phospholipid-binding protein. It has been implicated in suppression of inflammation ${ }^{77-80}$ and is attenuated in obese individuals ${ }^{81}$. Akasheh ${ }^{82}$ and Warne ${ }^{83}$ et. al report ANXA1 deficient mice were leaner (as measured by epididymal fat pad weight) when compared to wild-type mice. Given our findings, we hypothesize that reduced activity of ANXA1 induced by physical activity may play a role in the reduction of adiposity.

Lim et al. ${ }^{84,85}$ have shown that YWHAZ depleted mice have improved glucose tolerance and significant reductions in adipose tissue, while overexpression of YWHAZ results in impaired insulin sensitivity and expansion of adipose tissue. We hypothesize that reduced YWHAZ expression induced by physical activity is associated with reduced adiposity.

High expression levels of PNP - a gene responsible for producing purine nucleoside phosphorylase enzyme - have been associated with higher purine content in the body ${ }^{86}$, a condition associated with increased risk of hyperuricemia and gout. Hyperuricemia and gout are known risk factors for cardiovascular disease, renal disease, insulin resistance, obesity and other metabolic diseases ${ }^{87-90}$. Given that decreased PNP is associated with decreased BMI in our twins cohort, we hypothesize that physical activity may play a role in the reduction of adiposity through regulation of the purine metabolism pathway. Heid et. al conducted a meta-analysis of 32 genome-wide association studies $^{91}$ and identified SSPN as one of the 13 loci associated with waist-to-hip ratio and other measures of adiposity. More recently, Voisin et al. ${ }^{92}$ and Keller et al. ${ }^{93}$ have identified SSPN, the sarcospan gene, to be significantly and negatively associated with BMI through epigenome-wide analysis. Based on these and our findings, we hypothesize that attenuation of SSPN induced by physical activity may reduce adiposity.

We found that aerobic and anaerobic physical activity alter the expression of a core set of genes. There is some evidence to support the role of both aerobic and anaerobic PA in decreasing risk for disease. For example, Sigal et. $\mathrm{al}^{94}$ in a randomized clinical trial to determine the optimal exercise modality for obese adolescents, found that body mass index (BMI) was decreased for aerobic groups $(-1.0(-1.7,-0.3))$ and anaerobic groups $(0.9(-1.7,-0.1))$ but had a higher effect sizes for the combined exercise group $(-2.0(-2.7,-1.2))$. We claim that these two forms of exercise have similar routes for mitigation of disease risk, such as obesity.

\section{Physical Activity and White Blood Cell Count}

We hypothesize that physical activity regulation of genes such as ANXA1 may play a role in inflammatory-related phenotypes. For example, observationally, physical activity has been associated with reduced inflammation in the body $^{95,96}$. In our investigation, we identified thirteen PA signature genes to be significantly associated and discordant in direction (12 out of 13 transcripts) with white blood cell count. Of these, ANXA1, YWHAZ, and IL18RI have been associated with inflammation in prior studies ${ }^{79,97-103}$. ANXA1, an anti-inflammatory protein annexin A1, for example, was found to be strongly expressed in Alzheimer's disease and has been shown to promote resolution of inflammatory microglial activation ${ }^{98}$ and the clearance and degradation of amyloid-peptide ${ }^{99}$.

\section{Physical Activity and Age Deceleration in Brain Tissue}

We identified three PA signature genes, PNPLA7, SSPN, and NAPEPLD, identified in blood/muscle tissue to be significantly associated $(\mathrm{p}<0.05)$ and concordant in direction with age deceleration measured in brain tissue. These transcripts, PNPLA7, SSPN, and NAPEPLD are expressed in muscle, blood and brain tissue with NAPEPLD having high levels of expression in brain tissue ${ }^{52}$. NAPEPLD, $\mathrm{N}$-acyl phosphatidylethanolamine phospholipase $\mathrm{D}$, has been previously studied in the context of brain activity ${ }^{104}$ and $S S P N$ has been associated with muscle regeneration ${ }^{105}$. We posit that physical activity regulation of PNPLA7, SSPN, and NAPEPLD in blood/muscle tissue is associated with age deceleration in the brain. This has significant clinical implications potentially providing a cost-effective and minimally invasive mechanism for measuring age deceleration. 


\section{Limitations}

While, to our knowledge, we have reported largest study to-date in gene expression differences in physical activity, our study has several limitations. First, our meta-analysis spans a broad range of age groups, from 8 year olds to individuals in their 60s. While we have identified transcripts that are significantly differentially expressed across this age span, we may have potentially missed some age specific signatures of physical activity. In a similar vein, our meta-analysis does not focus on sex-specific regulation of genes induced by physical activity. Second, while we ensured uniformity of physical activity intervention with respect to time duration, we could not fully ensure uniform intervention (for example, type of strengthening exercises, equipment used etc.). This could potentially alter effect sizes/significance of identified genes. Third, we used both blood and muscle tissues in our meta-analysis ( $2 / 3$ of the tissue was blood). This could potentially bias our results perhaps warranting additional analysis with more muscle samples, and other pathologically relevant tissues, such as liver, adipose, and brain. Fourth, our population for the meta-analysis is largely homogeneous (non-Hispanic white, based on the studies that reported ethnicity). Our discovered PA associated genes may not hold true for a heterogeneous population. These results must be validated in an ethnically diverse population to be generally applicable. Fifth, we make extrapolations in aging associations in brain tissue, when our expression signature was derived from blood tissue. Others have documented modest to null correlation of blood gene expression to that in brain, so our brain-related associations require replication. Sixth, we found little association between major depressive disorder and physical activity. This could potentially be due to the small number of cases in our twin cohort and requires replication in a larger cohort.

\section{Conclusions}

Our analysis show that physical activity induces differentiation of thirty genes, with 20 transcripts over-expressed and 10 transcripts down-regulated. Further, we find several of the PA significant genes are associated with body mass index, white blood cell count, and age deceleration. We find that phenotype-associated genes up-regulated by physical activity were found to be down-regulated in body mass index and white blood cell count, and up-regulated in age deceleration and vice versa. These findings establish a directionally consistent molecular link between physical activity and these phenotypes, under-scoring the potential therapeutic benefits of physical activity.

There are several outstanding questions. While our results highlight the common molecular effects of aerobic and anaerobic exercise, the differences in the molecular signature induced by aerobic vs anaerobic exercise and their biomedical relevance is an open question. There have been prior observational studies detailing the effect of exercise modality on phenotypes (waist circumference, percentage of body fat) ${ }^{94,106}$ but the changes in the gene expression caused by the different exercise modalities and their association with body mass index or aging has not been studied. Second, while our work has measured the genes modulated via physical activity, it is unclear how long, in terms of time duration, these modifications to the gene expressions persist. Stratifying gene expressions by the minutes/hours of physical activity per week/month can provide potential insights into this question and potentially a molecular basis for recommendations on daily/weekly levels of physical activity. Third, while we have identified PA signature genes, additional validation in an independent cohort is required to develop a generalized PA predictor to determine the physical activity in individuals. Fourth, physical activity is a therapeutic for many chronic conditions. We have examined the associations between physical activity and body mass index, white blood cell count and healthy aging. Further investigations are needed to identify molecular level associations of physical activity with other chronic conditions such as Alzheimer's disease.

\section{References}

1. Lee, O., Lee, D.-C., Lee, S. \& Kim, Y. S. Associations between physical activity and obesity defined by Waist-To-Height ratio and body mass index in the korean population. PLoS One 11, e0158245 (2016).

2. Ruotsalainen, H., Kyngäs, H., Tammelin, T. \& Kääriäinen, M. Systematic review of physical activity and exercise interventions on body mass indices, subsequent physical activity and psychological symptoms in overweight and obese adolescents. J. Adv. Nurs. 71, 2461-2477 (2015). 
3. Daskalopoulou, C. et al. Physical activity and healthy ageing: A systematic review and meta-analysis of longitudinal cohort studies. Ageing Res. Rev. 38, 6-17 (2017).

4. DiPietro, L. Physical activity in AgingChanges in patterns and their relationship to health and function. $J$. Gerontol. A Biol. Sci. Med. Sci. 56, 13-22 (2001).

5. Ahlskog, J. E., Geda, Y. E., Graff-Radford, N. R. \& Petersen, R. C. Physical exercise as a preventive or disease-modifying treatment of dementia and brain aging. Mayo Clin. Proc. 86, 876-884 (2011).

6. Patel, C. J., Manrai, A. K., Corona, E. \& Kohane, I. S. Systematic correlation of environmental exposure and physiological and self-reported behaviour factors with leukocyte telomere length. Int. J. Epidemiol. 46, 44-56 (2017).

7. Patel, C. J. et al. Systematic evaluation of environmental and behavioural factors associated with all-cause mortality in the united states national health and nutrition examination survey. Int. J. Epidemiol. 42, 1795-1810 (2013).

8. Thompson, P. D. et al. Exercise and physical activity in the prevention and treatment of atherosclerotic cardiovascular disease: a statement from the council on clinical cardiology (subcommittee on exercise, rehabilitation, and prevention) and the council on nutrition, physical activity, and metabolism (subcommittee on physical activity). Circ. 107, 3109-3116 (2003).

9. Powell, K. E., Thompson, P. D., Caspersen, C. J. \& Kendrick, J. S. Physical activity and the incidence of coronary heart disease. Annu. Rev. Public Heal. 8, 253-287 (1987).

10. Lavie, C. J. et al. Exercise and the cardiovascular system: clinical science and cardiovascular outcomes. Circ. Res. 117, 207-219 (2015).

11. Paffenbarger, R. S., Jr, Jung, D. L., Leung, R. W. \& Hyde, R. T. Physical activity and hypertension: an epidemiological view. Ann. Med. 23, 319-327 (1991).

12. Warburton, D. E. R., Nicol, C. W. \& Bredin, S. S. D. Health benefits of physical activity: the evidence. CMAJ 174, 801-809 (2006).

13. Diaz, K. M. \& Shimbo, D. Physical activity and the prevention of hypertension. Curr. Hypertens. Rep. 15, 659-668 (2013).

14. Lautenschlager, N. T. et al. Effect of physical activity on cognitive function in older adults at risk for alzheimer disease: a randomized trial. JAMA 300, 1027-1037 (2008).

15. Rovio, S. et al. Leisure-time physical activity at midlife and the risk of dementia and alzheimer's disease. Lancet Neurol. 4, 705-711 (2005).

16. Buchman, A. S. et al. Total daily physical activity and the risk of $\mathrm{AD}$ and cognitive decline in older adults. Neurol. 78, 1323-1329 (2012).

17. Stephen, R., Hongisto, K., Solomon, A. \& Lönnroos, E. Physical activity and alzheimer's disease: A systematic review. J. Gerontol. A Biol. Sci. Med. Sci. 72, 733-739 (2017).

18. Hamer, M. \& Chida, Y. Physical activity and risk of neurodegenerative disease: a systematic review of prospective evidence. Psychol. Med. 39, 3-11 (2009).

19. Ahlskog, J. E. Does vigorous exercise have a neuroprotective effect in parkinson disease? Neurol. 77, 288-294 (2011).

20. Knowler, W. C. et al. Reduction in the incidence of type 2 diabetes with lifestyle intervention or metformin. $N$. Engl. J. Med. 346, 393-403 (2002).

21. Cox, D. J. et al. Glycemic load, exercise, and monitoring blood glucose (GEM): A paradigm shift in the treatment of type 2 diabetes mellitus. Diabetes Res. Clin. Pract. 111, 28-35 (2016). 
22. Ryan, A. S. Improvements in insulin sensitivity after aerobic exercise and weight loss in older women with a history of gestational diabetes and type 2 diabetes mellitus. Endocr. Res. 41, 132-141 (2016).

23. Aune, D., Norat, T., Leitzmann, M., Tonstad, S. \& Vatten, L. J. Physical activity and the risk of type 2 diabetes: a systematic review and dose-response meta-analysis. Eur. J. Epidemiol. 30, 529-542 (2015).

24. Singh, S., Devanna, S., Edakkanambeth Varayil, J., Murad, M. H. \& Iyer, P. G. Physical activity is associated with reduced risk of esophageal cancer, particularly esophageal adenocarcinoma: a systematic review and meta-analysis. BMC Gastroenterol. 14, 101 (2014).

25. Wolin, K. Y., Yan, Y., Colditz, G. A. \& Lee, I.-M. Physical activity and colon cancer prevention: a meta-analysis. Br. J. Cancer 100, 611-616 (2009).

26. Slattery, M. L. Physical activity and colorectal cancer. Sports Med. 34, 239-252 (2004).

27. Lahart, I. M., Metsios, G. S., Nevill, A. M. \& Carmichael, A. R. Physical activity, risk of death and recurrence in breast cancer survivors: A systematic review and meta-analysis of epidemiological studies. Acta Oncol. 54, 635-654 (2015).

28. Rebar, A. L. et al. A meta-meta-analysis of the effect of physical activity on depression and anxiety in non-clinical adult populations. Heal. Psychol. Rev. 9, 366-378 (2015).

29. Butterfield, N. et al. Type 2 diabetes rates quadruple worldwide since 1980. http://www . medscape. com/viewarticle/861591 (2016). Accessed: 2017-4-17.

30. Organization, W. H. WHO — diabetes (2016).

31. Organization, W. H. WHO - obesity and overweight (2016).

32. Turan, N. et al. A systems biology approach identifies molecular networks defining skeletal muscle abnormalities in chronic obstructive pulmonary disease. PLoS Comput. Biol. 7, e1002129 (2011).

33. Lanza, I. R. et al. Endurance exercise as a countermeasure for aging. Diabetes 57, 2933-2942 (2008).

34. Radom-Aizik, S., Zaldivar, F., Leu, S.-Y., Galassetti, P. \& Cooper, D. M. Effects of $30 \mathrm{~min}$ of aerobic exercise on gene expression in human neutrophils. J. Appl. Physiol. 104, 236-243 (2007).

35. Radom-Aizik, S., Zaldivar, F., Leu, S.-Y., Cooper, D. M. \& Cooper, D. M. A brief bout of exercise alters gene expression and distinct gene pathways in peripheral blood mononuclear cells of early- and late-pubertal females. J. Appl. Physiol. 107, 168-175 (2009).

36. Radom-Aizik, S., Zaldivar, F., Haddad, F. \& Cooper, D. M. Impact of brief exercise on peripheral blood NK cell gene and microRNA expression in young adults. J. Appl. Physiol. 114, 628-636 (2013).

37. Radom-Aizik, S., Zaldivar, F. P., Haddad, F. \& Cooper, D. M. Impact of brief exercise on circulating monocyte gene and microRNA expression: implications for atherosclerotic vascular disease. Brain Behav. Immun. 39, 121-129 (2014).

38. Phillips, B. E. et al. Molecular networks of human muscle adaptation to exercise and age. PLoS Genet. 9, e1003389 (2013).

39. Zambon, A. C. et al. Time- and exercise-dependent gene regulation in human skeletal muscle. Genome Biol. 4, R61 (2003).

40. Simonian, R. D. \& Laird, N. Meta-Analysis in clinical trials. Control. Clin. Trials 7, 177-188 (1986).

41. Kang, D. D., Sibille, E., Kaminski, N. \& Tseng, G. C. MetaQC: objective quality control and inclusion/exclusion criteria for genomic meta-analysis. Nucleic Acids Res. 40, e15-e15 (2012).

42. Sweeney, T. E., Haynes, W. A., Vallania, F., Ioannidis, J. P. \& Khatri, P. Methods to increase reproducibility in differential gene expression via meta-analysis. Nucleic Acids Res. 45 (2017).

43. Haynes, W. A. et al. EMPOWERING MULTI-COHORT GENE EXPRESSION ANALYSIS TO INCREASE REPRODUCIBILITY. Pac. Symp. Biocomput. 22, 144-153 (2016). 
44. Barrett, T. \& Edgar, R. Mining microarray data at NCBI \'s gene expression omnibus (GEO)*. In Gene Mapping, Discovery, and Expression, 175-190 (Humana Press, New Jersey, 2013).

45. Kolesnikov, N. et al. ArrayExpress update-simplifying data submissions. Nucleic Acids Res. 43, D1113-6 (2015).

46. Winter, D. rentrez: Entrez in R (2017). URL https : / / CRAN.R-project.org/package=rentrez. $\mathrm{R}$ package version 1.1.0.

47. Kauffmann, A. et al. Importing arrayexpress datasets into r/bioconductor. Bioinforma. 25, 2092-4 (2009).

48. Zhu, Y., Davis, S., Stephens, R., Meltzer, P. S. \& Chen, Y. Geometadb: powerful alternative search engine for the gene expression omnibus. Bioinforma. (Oxford, England) 24, 2798-2800 (2008). URL http: //www.ncbi.nlm.nih.gov/pubmed/18842599. DOI 10.1093/bioinformatics/btn520.

49. AM Fox, W. H. The exercise stress test: needs for standardization. Cardiol. Curr. topics progress 3, 149-154 (1971).

50. Tanaka, H., Monahan, K. D. \& Seals, D. R. Age-predicted maximal heart rate revisited. J. Am. Coll. Cardiol. 37, 153-156 (2001).

51. Carpinelli, R. N., Otto, R. M. \& Winett, R. A. A critical analysis of the ACSM position stand on resistance training: insufficient evidence to support recommended training protocols. Prof. Exerc. Physiol. 7 (2004).

52. of MIT, T. B. I. \& Harvard. GTEx portal. https : / /www . gtexportal . org/home/. Accessed: 2017 8-29.

53. Bolstad, B. M., Irizarry, R. A., Astrand, M. \& Speed, T. P. A comparison of normalization methods for high density oligonucleotide array data based on variance and bias. Bioinforma. 19, 185-193 (2003).

54. Johnson, W. E., Li, C. \& Rabinovic, A. Adjusting batch effects in microarray expression data using empirical bayes methods. Biostat. 8, 118-127 (2007).

55. DerSimonian, R. \& Kacker, R. Random-effects model for meta-analysis of clinical trials: An update. Contemp. Clin. Trials 28, 105-114 (2007).

56. Viechtbauer, W. Conducting Meta-Analyses in $R$ with the metafor package. J. Stat. Softw. 36, 1-48 (2010).

57. Higgins, J. P. T. \& Thompson, S. G. Quantifying heterogeneity in a meta-analysis. Stat. Med. 21, 1539-1558 (2002).

58. Horvath, S. DNA methylation age of human tissues and cell types. Genome Biol. 14, R115 (2013).

59. Carlin, J. B., Gurrin, L. C., Sterne, J. A., Morley, R. \& Dwyer, T. Regression models for twin studies: a critical review. Int. J. Epidemiol. 34, 1089-1099 (2005).

60. Visscher, P. M., Benyamin, B. \& White, I. The use of linear mixed models to estimate variance components from data on twin pairs by maximum likelihood. Twin Res. 7, 670-674 (2004).

61. Bahadır, A. et al. Is the neutrophil-to-lymphocyte ratio indicative of inflammatory state in patients with obesity and metabolic syndrome? Anatol J Cardiol 15, 816-822 (2015).

62. Kantor, E. D., Lampe, J. W., Kratz, M. \& White, E. Lifestyle factors and inflammation: associations by body mass index. PLoS One 8, e67833 (2013).

63. Smith, M. R. et al. Smoking status and differential white cell count in men and women in the EPIC-Norfolk population. Atheroscler. 169, 331-337 (2003).

64. Fernández, J. A. F. et al. Systemic inflammation in 222.841 healthy employed smokers and nonsmokers: white blood cell count and relationship to spirometry. Tob. Induc. Dis. 10, 7 (2012).

65. Boden, J. M. \& Fergusson, D. M. Alcohol and depression. Addict. 106, 906-914 (2011). 
66. Bates, D., Mächler, M., Bolker, B. \& Walker, S. Fitting linear mixed-effects models using lme4. J. Stat. Softw. 67, 1-48 (2015). DOI 10.18637/jss.v067.i01.

67. Alexandra Kuznetsova, R. H. B. C., Per Bruun Brockhoff. lmertest r package (2015).

68. Batista, G. E. \& Monard, M. C. A study of K-Nearest neighbour as an imputation method. HIS (2002).

69. Teschendorff, A. E. et al. A beta-mixture quantile normalization method for correcting probe design bias in illumina infinium 450 k DNA methylation data. Bioinforma. 29, 189-196 (2013).

70. Levine, M. E., Lu, A. T., Bennett, D. A. \& Horvath, S. Epigenetic age of the pre-frontal cortex is associated with neuritic plaques, amyloid load, and alzheimer's disease related cognitive functioning. Aging 7, 1198-1211 (2015).

71. Nie, X.-C. et al. COL4A3 expression correlates with pathogenesis, pathologic behaviors, and prognosis of gastric carcinomas. Hum. Pathol. 44, 77-86 (2013).

72. Jiang, C.-P. et al. High COL4A3 expression correlates with poor prognosis after cisplatin plus gemcitabine chemotherapy in non-small cell lung cancer. Tumour Biol. 34, 415-420 (2013).

73. Hunt, S. C. et al. Sodium bicarbonate cotransporter polymorphisms are associated with baseline and 10-year follow-up blood pressures. Hypertens. 47, 532-536 (2006).

74. Taylor, J. Y., Sampson, D., Taylor, A. D., Caldwell, D. \& Sun, Y. V. Genetic and BMI risks for predicting blood pressure in three generations of west african dogon women. Biol. Res. Nurs. 15, 105-111 (2013).

75. Gröger, N. et al. Targeted mutation of SLC4A5 induces arterial hypertension and renal metabolic acidosis. Hum. Mol. Genet. 21, 1025-1036 (2012).

76. Piñero, J. et al. DisGeNET: a comprehensive platform integrating information on human disease-associated genes and variants. Nucleic Acids Res. 45, D833-D839 (2017).

77. Perretti, M. \& Gavins, F. N. E. Annexin 1: an endogenous anti-inflammatory protein. News Physiol. Sci. 18, 60-64 (2003).

78. Perretti, M. \& D'Acquisto, F. Annexin A1 and glucocorticoids as effectors of the resolution of inflammation. Nat. Rev. Immunol. 9, 62-70 (2009).

79. Headland, S. E. et al. Neutrophil-derived microvesicles enter cartilage and protect the joint in inflammatory arthritis. Sci. Transl. Med. 7, 315 ra190 (2015).

80. Hayhoe, R. P. G. et al. Annexin 1 and its bioactive peptide inhibit neutrophil-endothelium interactions under flow: indication of distinct receptor involvement. Blood 107, 2123-2130 (2006).

81. Henegar, C. et al. Adipose tissue transcriptomic signature highlights the pathological relevance of extracellular matrix in human obesity. Genome Biol. 9, R14 (2008).

82. Akasheh, R. T., Pini, M., Pang, J. \& Fantuzzi, G. Increased adiposity in annexin a1-deficient mice. PLoS One 8, e82608 (2013).

83. Warne, J. P. et al. Gene deletion reveals roles for annexin A1 in the regulation of lipolysis and IL-6 release in epididymal adipose tissue. Am. J. Physiol. Endocrinol. Metab. 291, E1264-73 (2006).

84. Lim, G. E. et al. Ywhaz/14-3-3 $\zeta$ deletion improves glucose tolerance through a GLP-1-Dependent mechanism. Endocrinol. 157, 2649-2659 (2016).

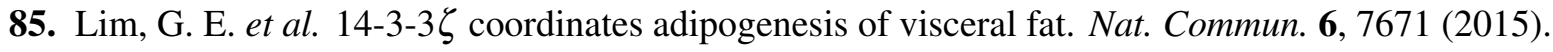

86. Moriwaki, Y., Yamamoto, T. \& Higashino, K. Enzymes involved in purine metabolism-a review of histochemical localization and functional implications. Histol. Histopathol. 14, 1321-1340 (1999).

87. Mahor, D., Priyanka, A., Prasad, G. S. \& Thakur, K. G. Functional and structural characterization of purine nucleoside phosphorylase from kluyveromyces lactis and its potential applications in reducing purine content in food. PLoS One 11, e0164279 (2016). 
88. Tsushima, Y. et al. Uric acid secretion from adipose tissue and its increase in obesity. J. Biol. Chem. 288, 27138-27149 (2013).

89. Gagliardi, A. C. M., Miname, M. H. \& Santos, R. D. Uric acid: A marker of increased cardiovascular risk. Atheroscler. 202, 11-17 (2009).

90. Lee, J., Sparrow, D., Vokonas, P. S., Landsberg, L. \& Weiss, S. T. Uric acid and coronary heart disease risk: Evidence for a role of uric acid in the Obesity-Insulin resistance SyndromeThe normative aging study. Am. J. Epidemiol. 142, 288-294 (1995).

91. Heid, I. M. et al. Meta-analysis identifies 13 new loci associated with waist-hip ratio and reveals sexual dimorphism in the genetic basis of fat distribution. Nat. Genet. 42, 949-960 (2010).

92. Voisin, S. et al. Many obesity-associated SNPs strongly associate with DNA methylation changes at proximal promoters and enhancers. Genome Med. 7, 103 (2015).

93. Keller, M. et al. Genome-wide DNA promoter methylation and transcriptome analysis in human adipose tissue unravels novel candidate genes for obesity. Mol Metab 6, 86-100 (2017).

94. Sigal, R. J. et al. Effects of aerobic training, resistance training, or both on percentage body fat and cardiometabolic risk markers in obese adolescents: the healthy eating aerobic and resistance training in youth randomized clinical trial. JAMA Pediatr. 168, 1006-1014 (2014).

95. Abramson, J. L. \& Vaccarino, V. Relationship between physical activity and inflammation among apparently healthy middle-aged and older US adults. Arch. Intern. Med. 162, 1286-1292 (2002).

96. Kasapis, C. \& Thompson, P. D. The effects of physical activity on serum c-reactive protein and inflammatory markers: a systematic review. J. Am. Coll. Cardiol. 45, 1563-1569 (2005).

97. Sena, A. et al. Dysregulation of anti-inflammatory annexin A1 expression in progressive crohns disease. PLoS One 8, e76969 (2013).

98. McArthur, S. et al. Annexin a1: a central player in the anti-inflammatory and neuroprotective role of microglia. J. Immunol. 185, 6317-6328 (2010).

99. Ries, M. et al. The anti-inflammatory annexin A1 induces the clearance and degradation of the amyloid- $\beta$ peptide. J. Neuroinflammation 13, 234 (2016).

100. Miura, K. et al. Ehrlichia chaffeensis induces monocyte inflammatory responses through MyD88, ERK, and NF- $\kappa$ B but not through TRIF, interleukin-1 receptor 1 (IL-1R1)/IL-18R1, or toll-like receptors. Infect. Immun. 79, 4947-4956 (2011).

101. Liangos, O. et al. Whole blood transcriptomics in cardiac surgery identifies a gene regulatory network connecting ischemia reperfusion with systemic inflammation. PLoS One 5, e13658 (2010).

102. Ignatius Irudayam, J. et al. Profile of inflammation-associated genes during hepatic differentiation of human pluripotent stem cells. Data Brief 5, 871-878 (2015).

103. Liu, H. et al. Identification of IL18RAP/IL18R1 and IL12B as leprosy risk genes demonstrates shared pathogenesis between inflammation and infectious diseases. Am. J. Hum. Genet. 91, 935-941 (2012).

104. Leung, D., Saghatelian, A., Simon, G. M. \& Cravatt, B. F. Inactivation of n-acyl phosphatidylethanolamine phospholipase D reveals multiple mechanisms for the biosynthesis of endocannabinoids. Biochem. 45, 47204726 (2006).

105. Marshall, J. L. et al. Dystrophin and utrophin expression require sarcospan: loss of $\alpha 7$ integrin exacerbates a newly discovered muscle phenotype in sarcospan-null mice. Hum. Mol. Genet. 21, 4378-4393 (2012).

106. Lee, S. et al. Effects of aerobic versus resistance exercise without caloric restriction on abdominal fat, intrahepatic lipid, and insulin sensitivity in obese adolescent boys: a randomized, controlled trial. Diabetes 61, 2787-2795 (2012). 